\title{
Methicillin-resistant Staphylococcus aureus nasal carriage among janitors working in hospital and non-hospital areas: a comparative cross-sectional study
}

Seid Abie, Moges Tiruneh and Wondwossen Abebe*

\begin{abstract}
Background: Nasal colonization of Methicillin-resistant Staphylococcus aureus (MRSA) plays a key role in the epidemiology and pathogenesis of both healthcare-associated and community-acquired MRSA infections in various populations. Screening of MRSA nasal colonization is important in the prevention and control of infection and may provide useful information to guide antimicrobial therapy. This study aimed to determine nasal carriage of MRSA, its antimicrobial susceptibility pattern, and associated factors among janitors working in hospital \& non-hospital areas at the University of Gondar, Northwest Ethiopia.
\end{abstract}

Methods: A comparative cross-sectional study was carried out in a total of 436 study participants (221 hospital and 215 non-hospital janitors) from January to May 2019. The study participants were sampled using a simple random sampling technique. Data on socio-demographic characteristics and associated factors were collected through face to face interviews using a structured questionnaire. Nasal swabs were collected and inoculated into Mannitol salt agar. MRSA was detected using cefoxitin $(30 \mu \mathrm{g})$ disc and an antibiotic susceptibility test was done using the disc diffusion method. Data were entered and analyzed using SPSS version 20 statistical package. $P$ value $\leq 0.05$ was considered as statistically significant.

Results: The overall prevalence of S. aureus was 101/436 [23.2\%, (95\% Cl: 19.3-27.8)], of which, 29.4\% (65/221) were isolated from hospital and 16.7\% (36/215) non-hospital janitors. The prevalence of MRSA was 4.8\% (21/436) [95\% Cl: 3.0-6.9]; of these, 8.1\% (18/221) of the isolates were from the hospital and 1.4\% (3/215) non-hospital janitors, while methicillin-sensitive S. aureus (MSSA) in hospital \& non-hospital janitors were $49(22.2 \%)$ and 31 (14.4\%), respectively. Among the MRSA isolates, 52.4\% (11/21) were multi-drug resistant. Of these, 42.9\% (9/18) were isolated from hospital and $66.7 \%(2 / 3)$ non-hospital janitors. Hence, nasal carriage of MRSA was significantly associated with hospitalization within the preceding year $(A O R=3.15, C l=1.13-8.71)$.

Conclusion: The present study revealed that high MSSA and MRSA were isolated from the hospital as compared to non-hospital janitors and high rates of antibiotics resistance were recorded in the hospital janitors. Consequently, hospitalizations were significantly associated with MRSA. Accordingly, regular screening of carriers in apparently healthy janitors is required for the prevention of nosocomial infections.

*Correspondence: wondisweet@gmail.com

Department of Medical Microbiology, School of Biomedical and Laboratory Sciences, College of Medicine and Health Sciences, University of Gondar, P.O.Box:196, Gondar, Ethiopia

c) The Author(s) 2020. This article is licensed under a Creative Commons Attribution 4.0 International License, which permits use, sharing, adaptation, distribution and reproduction in any medium or format, as long as you give appropriate credit to the original author(s) and the source, provide a link to the Creative Commons licence, and indicate if changes were made. The images or other third party material in this article are included in the article's Creative Commons licence, unless indicated otherwise in a credit line to the material. If material is not included in the article's Creative Commons licence and your intended use is not permitted by statutory regulation or exceeds the permitted use, you will need to obtain permission directly from the copyright holder. To view a copy of this licence, visit http://creativecommons.org/licenses/by/4.0/. The Creative Commons Public Domain Dedication waiver (http://creativecommons.org/publicdomain/zero/1.0/) applies to the data made available in this article, unless otherwise stated in a credit line to the data. 
Keywords: MRSA, Nasal carriage, Janitors, Antibiogram profile

\section{Background}

Methicillin-resistant Staphylococcus aureus (MRSA) is the most commonly reported multidrug-resistant pathogen in many parts of the world. The rapidly increasing rate of both healthcare-associated MRSA and community-acquired MRSA are major clinical, public health, and economic challenges $[1,2]$.

Nasal colonization of MRSA plays a key role in the epidemiology and pathogenesis of both healthcare-associated and community-acquired MRSA infection in various populations. It is estimated that up to $7.0 \%$ of people in hospitals and up to $2.0 \%$ of people in the community are carriers of MRSA infection. MRSA colonization can persist for months to years and the majority of colonized patients remain completely asymptomatic. Besides, MRSA nasal colonization is a risk factor for bacteremia, pneumonia, and skin infection. It is transmitted through person-to-person contact, environmental sources (like doorknobs and handrails), fomites, and companion animals [3-5].

Previous studies in Ethiopia have reported that the rate of nasal carriage of MRSA varying from $0 \%$ to $28.9 \%$ [6, 7]. A recent meta-analysis study conducted by Reta et. al showed that the pooled estimated prevalence of nasal colonization of MRSA was $10.94 \%$ [8].

Being a janitor is a predisposing risk factor to a different array of contaminated matter, cleaning agents, wet work, and polluted air \& dust. It is also associated with significant increases in respiratory and dermatologic diseases [9]. Besides, screening of MRSA nasal colonization is important in the prevention and control of infection and may provide useful information to guide antimicrobial therapy [3]. However, there are limited data in the study area and Ethiopia in this population [10]. Therefore, this study aimed to determine the prevalence of nasal carriage of MRSA, its antimicrobial susceptibility pattern, and associated factors among janitors working in hospital \& non-hospital areas at the University of Gondar, Northwest Ethiopia.

\section{Methods}

\section{Study area, design, and period}

A cross-sectional study was conducted from January to May 2019 among Janitors working in hospital \& nonhospital areas at the University of Gondar (UoG). The University of Gondar is one of the oldest and well established higher education institutions located $747 \mathrm{~km}$ Northwest of Addis Ababa, the capital city of Ethiopia. It has five campuses namely, College of Medicine and health sciences (CMHS), Maraki, Atse Tewdrose, Atse Fasil, and Tseda, and offers 138 undergraduate and 138 graduate programs. The CMHS has a referral teaching hospital with 700 beds, a maternal and child care hospital, a standard TB ward and laboratory, an eye hospital and Fistula center, and a general hospital that can give all other health services. According to the human resource directorate of the UoG, currently a total of 634 janitors working in the UoG, of which 243 are hospital janitors.

\section{Sample size and sampling technique}

The sample size was determined using Epi-info version 7 in double population proportion formulae. Taking the previous study done at Mekelle University, a 9.7\% prevalence of MRSA was used for janitors working in the hospital and $4.9 \%$ prevalence of MRSA for janitors working in the non-hospital areas (10). Considering the two prevalence rates, a power of $80 \%$ at a $95 \%$ confidence level with a 1:1 ratio the sample size was 1002 . Since the total number of the source population was less than 10,000 , the correction formula was used to adjust and it gives 392 . Finally, by considering a $10 \%$ non-response rate the final minimum sample size was 436 (221 hospitals and 215 non-hospital janitors). The study participants were sampled using a simple random sampling technique. In brief, a compressive list of janitors was obtained from the UoG human resource directorate office and the list was stratified into a hospital and non-hospital janitors. The selection was performed using simple random sampling by lottery methods until we get a preferred sample in each group.

\section{Data collection}

Data were collected through face to face interview using a structured questionnaire containing information on basic demographic characteristics and possible risk factors for colonization of MRSA such as age, gender, education level, job durations, workplace, use of antibiotics, recent respiratory and skin infections, presence of wounds and allergies, recent hospitalization, having a child, exposure to infectious waste and living with the hospitalized person.

\section{Specimen collection, processing, and identification}

A nasal swab was collected from each anterior nare using a sterile moistened swab. Each swab was rubbed five times against the anterior $1 \mathrm{~cm}$ of the nasal vestibular wall of both nares and immediately placed into Tryptose soya broth (Oxoid Ltd., Basingstoke, UK). The specimens 
were transported to the University of Gondar Medical Microbiology Laboratory in a cold box with ice-packs within $1 \mathrm{~h}$ of collection for further processing. The swabs were directly inoculated onto Mannitol salt agar (Oxoid Ltd. England), incubated at $37{ }^{\circ} \mathrm{C}$ for $48 \mathrm{~h}$, and left at room temperature to stimulate pigment formation. The isolates were characterized as S.aureus based on morphology, Gram stain, catalase test, coagulase test, and mannitol salt agar fermentation [10].

\section{Antimicrobial susceptibility test}

Antimicrobial susceptibility testing was performed on Muller Hinton Agar (Oxoid, UK) using the disc diffusion method against penicillin G (10 units), gentamicin $(10 \mu \mathrm{g})$, erythromycin $(15 \mu \mathrm{g})$, tetracycline $(30 \mu \mathrm{g})$, trimethoprim/sulphamethoxazole $(25 \mu \mathrm{g})$, ciprofloxacin $(5 \mu \mathrm{g})$, clindamycin $(15 \mu \mathrm{g})$ and cefoxitin $(30 \mu \mathrm{g})$ based on the guidelines adapted from Clinical and Laboratory Standards Institute (CLSI 2019 edition); the results were reported as sensitive, intermediate and resistance as previously described by CLSI [11]. Besides, MRSA strains were differentiated from methicillin-sensitive S.aureus (MSSA) strains using cefoxitin $(30 \mu \mathrm{g})$ disc, S.aureus with a zone of inhibition of $\leq 21 \mathrm{~mm}$ was considered to be MRSA phenotypically [11]. Multidrug resistance (MDR) is defined as the resistance of an isolate to three and more antimicrobial classes [12]. S. aureus American Type Culture Collection (ATCC) 43300 (MRSA) and ATCC 25923 (MSSA) were used as the quality control strain [11].

\section{Data analysis and interpretation}

Data were entered and analyzed using SPSS version 20 software. Descriptive statistics were employed and binary logistic regression analysis was used to check the association between dependent and independent variables with odds ratio at $95 \%$ confidence intervals. All independent variables with $p$-value $\leq 0.2$ in the bivariate analysis were included in a multivariate logistic regression model. $\mathrm{P}$-value $\leq 0.05$ in multivariate analysis was considered as statistical significance.

\section{Results}

\section{Characteristics of the Study participants}

A total of 436 study participants (221 hospital and 215 non-hospital janitors) were included in this study. The majority of the janitors were females, 420 (96.3\%) and their ages ranged from 18 to 58 years with a mean age of $28.15 \pm 6.3$ years. Three hundred one $(69 \%)$ of the participants had attended college \& above and 259 (59.4\%) were married. Most of the janitors had served less than 2 years (52.1\%). Hundred eighty-five (42.4\%) suffered from allergic rhinitis and 221 (52.0\%) had exposure to waste \& body fluids. However, 173 (39.7\%) participants suffered from respiratory tract infection in the last 3 months, 128 (29.4\%) had skin infections, $170(40 \%)$ were prescribed antibiotics for the last 3 months, 119 (27.3\%) were currently living with children, and 105 (24.9\%) lived with a hospitalized person (Table 1).

\section{Nasal carriage of MSSA and MRSA among hospital and non-hospital janitors}

The nasal carriage rate of $S$. aureus was $23.2 \%(101 / 436)$. Of these, $29.4 \%(65 / 221)$ were isolated from hospital and $16.7 \%(36 / 215)$ non-hospital janitors. There was a statistically significant difference in the isolation frequency of $S$. aureus among hospital and non-hospital janitors $(p=0.013)$. The prevalence of MSSA and MRSA was $18.3 \%(80 / 436)$ and $4.8 \%(21 / 436)$, respectively. Among 21 MRSA isolates, $8.1 \%(18 / 221)$ were from the hospital and $1.4 \%(3 / 215)$ non-hospital janitors, while MSSA in hospital \& non-hospital janitors were 49 (22.2\%) and 31 (14.4\%), respectively. There was no significant association between the carriage rate of MRSA/MSSA and the workplace $(p=0.092)($ Table 2$)$.

\section{Antimicrobial susceptibility testing}

Table 3 presents antibiotic resistance patterns of 101 S.aureus (MRSA \& MSSA) strains isolated from 436 study participants. Overall, 31.7\% (32/101) isolates were resistant to three or more classes of antibiotics tested (MDR). Of these, $20.8 \%(21 / 101)$ were MSSA and 10.9\% (11/101) were MRSA. Among the total of 80 MSSA isolates, $26.3 \%$ (21/80) were MDR. Of these, $36.7 \%$ (18/49) were isolated from nasal nares of the hospital and 9.7\% (3/31) nonhospital janitors. Among the total of 21 MRSA isolates, $52.4 \%(11 / 21)$ were MDR. Of these, $42.9 \%$ (9/18) were isolated from nasal nares of the hospital and $66.7 \%(2 / 3)$ non-hospital janitors. MRSA isolates were resistance to penicillin 21(100\%), trimethoprim/sulphamethoxazole 9(42.9\%), ciprofloxacin 8(38.1\%), tetracycline 7(33.3\%), erythromycin 5(23.8\%), gentamicin 5(23.8\%), and clindamycin 4(19\%). MSSA isolates were resistance to penicillin 78(97.5\%), trimethoprim/sulphamethoxazole 13(30.0\%), ciprofloxacin $7(8.8 \%)$, tetracycline $16(20 \%)$, erythromycin 17 (21.3\%), gentamicin $16.3 \%$ and clindamycin 2(2.5\%). Accordingly, there was a statistically significant difference of resistance to tetracycline, gentamicin, ciprofloxacin, and clindamycin between the hospital and non-hospital isolates $(p<0.05)$.

Factor associated with nasal carriage of S.aureus and MRSA In multivariate logistic analysis, associations were observed between nasal carriage of S.aureus and work place $(\mathrm{AOR}=2.12,95 \% \mathrm{CI}=1.17-3.86)$, respiratory tract infection ( $\mathrm{AOR}=2.37,95 \% \mathrm{CI}=1.02-5.46)$, skin infection $(\mathrm{AOR}=6.37,95 \% \mathrm{CI}=3.61-11.77)$, wound infection 
Table 1 Descriptive characteristic of janitors working in the hospital and non-hospital areas at the UoG, Northwest Ethiopia, 2019

\begin{tabular}{|c|c|c|c|}
\hline \multirow[t]{2}{*}{ Variables } & \multicolumn{2}{|l|}{ Workplace } & \multirow[t]{2}{*}{ Total $(n=436)$} \\
\hline & Hospital $(n=221)$ & Non-hospital $(n=215)$ & \\
\hline \multicolumn{4}{|l|}{ Sex } \\
\hline Male & $12(5.4)$ & $4(1.9)$ & $16(3.7)$ \\
\hline Female & $209(94.6)$ & $211(98.1)$ & $420(96.3)$ \\
\hline Mean (SD) Age (range) & $30.22 \pm 7.8(18-58)$ & $26.0 \pm 3.17(20-39)$ & $28.15 \pm 6.3(18-58)$ \\
\hline \multicolumn{4}{|l|}{ Age group(years) } \\
\hline $18-25$ & $65(29.4)$ & $102(47.4)$ & $167(33.3)$ \\
\hline$>25$ & $102(47.4)$ & $113(52.6)$ & $269(61.7)$ \\
\hline \multicolumn{4}{|l|}{ Marital status } \\
\hline Single & $91(41.2)$ & $56(26)$ & $147(33.7)$ \\
\hline Married & $121(54.8)$ & $138(64.2)$ & $259(59.4)$ \\
\hline Divorced & $9(4.1)$ & $21(9.8)$ & $30(6.9)$ \\
\hline \multicolumn{4}{|l|}{ Educational status } \\
\hline No formal education & $7(3.2)$ & 0 & $7(1.6)$ \\
\hline Secondary school & $103(46.6)$ & 25 (16.6) & $128(29.4)$ \\
\hline College and above & $111(50.2)$ & $190(88.4)$ & $301(69)$ \\
\hline \multicolumn{4}{|c|}{ Currently living with children } \\
\hline Yes & $64(28.9)$ & $55(25.6)$ & $119(27.3)$ \\
\hline No & $157(71.1)$ & $160(74.4)$ & $317(72.7)$ \\
\hline \multicolumn{4}{|c|}{ Prescribed antibiotics in the last 3 months } \\
\hline Yes & $105(47.5)$ & $65(44.2)$ & $170(40)$ \\
\hline No & $116(52.5)$ & $150(55.8)$ & $266(60)$ \\
\hline \multicolumn{4}{|c|}{ Respiratory tract infection in the last 3 months } \\
\hline Yes & $98(44.3)$ & $55(39.5)$ & $153(35.1)$ \\
\hline No & $123(55.7)$ & $160(60.5)$ & $283(64.9)$ \\
\hline \multicolumn{4}{|l|}{ Allergies } \\
\hline Yes & $67(30.3)$ & $118(54.9)$ & $185(42.4)$ \\
\hline No & $154(69.7)$ & $97(45.1)$ & $251(57.6)$ \\
\hline \multicolumn{4}{|c|}{ Skin infection in the last 3 months } \\
\hline Yes & $98(44.3)$ & $30(14)$ & $128(29.4)$ \\
\hline No & $123(55.7)$ & $185(86)$ & $308(70.6)$ \\
\hline \multicolumn{4}{|c|}{ Wound infection in the last 3 months } \\
\hline Yes & $50(22.6)$ & $38(17.7)$ & $88(20.2)$ \\
\hline No & $171(77.4)$ & $177(82.3)$ & $348(79.8)$ \\
\hline \multicolumn{4}{|l|}{ Exposed to body fluids } \\
\hline Yes & $83(37.6)$ & $128(59.5)$ & $221(50.7)$ \\
\hline No & $128(62.4)$ & $87(40.5)$ & $215(49.3)$ \\
\hline \multicolumn{4}{|c|}{ Hospital stays in the last 3 months } \\
\hline Yes & $50(22.6)$ & $12(5.6)$ & $62(14.2)$ \\
\hline No & $171(77.4)$ & $203(94.4)$ & $374(85.8)$ \\
\hline \multicolumn{4}{|c|}{ Living with a hospitalized person } \\
\hline Yes & $67(30.3)$ & $38(17.7)$ & $105(24.1)$ \\
\hline No & $154(69.7)$ & $177(82.3)$ & $331(75.1)$ \\
\hline \multicolumn{4}{|c|}{ Total job duration as a janitor } \\
\hline$<2$ years & $125(56.6)$ & $102(47.4)$ & $227(52.1)$ \\
\hline$\geq 2$ years & $96(43.4)$ & $113(52.6)$ & $209(47.9)$ \\
\hline
\end{tabular}


Table 2 Nasal carriage of S. aureus and MRSA among hospital and non-hospital janitors working at the UoG, Northwest Ethiopia, 2019

\begin{tabular}{|c|c|c|c|c|c|}
\hline & Hospital janitors (n, \%) & $\begin{array}{l}\text { Non-hospital janitors } \\
(n, \%)\end{array}$ & Total (n, \%) & OR $(95 \% \mathrm{Cl})$ & $P$ value \\
\hline Number of participants & 221 & 215 & 436 & & \\
\hline S.aureus & $65(29.4)$ & $36(16.7)$ & $101(23.2)$ & $2.127(1.170-3.866)$ & 0.013 \\
\hline MSSA & $49(22.2)$ & $31(14.4)$ & $80(18.3)$ & $1.490(0.912-2.435)$ & 0.112 \\
\hline MRSA & $18(8.1)$ & $3(1.4)$ & $21(4.8)$ & $3.294(0.822-13.195)$ & 0.092 \\
\hline
\end{tabular}

MRSA Methicillin resistant S.aureus, MSSA Methicillin susceptible S.aureus

Table 3 Antibiogram profile of MRSA \& MSSA, isolated from janitors working in the hospital and non-hospital areas at the UoG, Northwest Ethiopia, 2019

\begin{tabular}{|c|c|c|c|c|c|c|c|}
\hline \multirow[t]{2}{*}{ Antibiogram pattern } & \multicolumn{2}{|c|}{$\begin{array}{l}\text { Nasal carriage of MRSA } \\
(n=21)\end{array}$} & \multirow[t]{2}{*}{$\begin{array}{l}\text { MDR pattern } \\
\text { of MRSA }\end{array}$} & \multirow[t]{2}{*}{ Antibiogram pattern } & \multicolumn{2}{|c|}{$\begin{array}{l}\text { Nasal carriage of MSSA } \\
(n=80)\end{array}$} & \multirow{2}{*}{$\begin{array}{l}\text { MDR } \\
\text { pattern } \\
\text { of MSSA }\end{array}$} \\
\hline & $\mathrm{HJ}(\mathrm{n}=18)$ & $\mathrm{N}-\mathrm{HJ}(\mathrm{n}=3)$ & & & $\mathrm{HJ}(\mathrm{n}=49)$ & $\mathrm{N}-\mathrm{HJ}(\mathrm{n}=31)$ & \\
\hline PEN & 0 & 0 & 0 & PEN & 20 & 19 & 39 \\
\hline PEN \& ERY & 2 & 0 & 2 & TET & 1 & 0 & 1 \\
\hline PEN \& CLI & 2 & 0 & 2 & ERY & 0 & 1 & 1 \\
\hline PEN \& SXT & 2 & 1 & 3 & PEN \& ERY & 5 & 1 & 6 \\
\hline PEN \& CIP & 3 & 0 & 3 & PEN \& GEN & 3 & 2 & 5 \\
\hline PEN,GEN \& SXT & 1 & 1 & 2 & PEN \& SXT & 1 & 4 & 5 \\
\hline PEN, TET \& CLI & 1 & 0 & 1 & PEN \& CLI & 1 & 0 & 1 \\
\hline PEN, TET\& SXT & 1 & 0 & 1 & PEN \& TET & 0 & 1 & 1 \\
\hline PEN, CIP\& SXT & 0 & 1 & 1 & PEN, SXT \& TET & 2 & 0 & 2 \\
\hline PEN, CIP,SXT \& ERY & 1 & 0 & 1 & PEN, GEN \& CIP & 1 & 0 & 1 \\
\hline PEN, TET, CLI \& SXT & 1 & 0 & 1 & PEN, GEN \& TET & 2 & 0 & 2 \\
\hline PEN, GEN,CLI, SXT \& ERY & 1 & 0 & 1 & PEN, TET \& ERY & 3 & 0 & 3 \\
\hline PEN, GEN,CIP,TET \& ERY & 1 & 0 & 1 & PEN,SXT \& ERY & 2 & 0 & 2 \\
\hline \multirow[t]{6}{*}{ PEN,GEN,CIP, TET \& SXT } & 2 & 0 & 2 & PEN, GEN, CIP \& TET & 2 & 1 & 3 \\
\hline & & & & PEN, GEN, TET \& SXT & 1 & 1 & 2 \\
\hline & & & & PEN, GEN,SXT \& ERY & 1 & 1 & 2 \\
\hline & & & & PEN, GEN, CLI, TET \& ERY & 1 & 0 & 1 \\
\hline & & & & PEN, GEN, CIP, TET \& ERY & 1 & 0 & 1 \\
\hline & & & & PEN, GEN, CIP, SXT \& ERY & 2 & 0 & 2 \\
\hline
\end{tabular}

$H J$ hospital janitors, $\mathrm{N}-\mathrm{H}$ J non-hospital janitors, MRSA Methicillin resistant S.aureus, MSSA Methicillin susceptible S.aureus, PEN Penicillin, ERY Erythromycin, CIP Ciprofloxacin, TETTetracycline, CLI Clindamycin, SXTTrimethoprim/sulphamethoxazole, GEN Gentamicin

$(\mathrm{AOR}=2.57,95 \% \mathrm{CI}=1.38-4.77)$ and living with hospitalized person $(\mathrm{AOR}=3.15, \quad 95 \% \mathrm{CI}=1.67-5.94)$. However, nasal carriage of MRSA was significantly associated with hospitalization within the preceding year $(\mathrm{AOR}=3.15, \mathrm{CI}=1.13-8.71)($ Table 4$)$.

\section{Discussion}

The present study reveals information on the nasal carriage of $S$. aureus and MRSA along with their antibiotic susceptibility pattern and factor associated among janitors working in the hospitals and non-hospital areas that play a decisive role to prevent future infection. The prevalence of nasal carriage $S$. aureus in this study was 23.2\%. This was consistent with those studies conducted among medical students in Jimma, Ethiopia (22.1\%) [12], and the poor urban community of San Francisco, USA $(22.8 \%)$ [13]. However, it was higher than the results of studies reported among janitors working in the hospital and non-hospital areas in Mekelle, Ethiopia (17.9\%) [10] and Taiwan (15.3\%) [14]. The overall prevalence of nasal carriage of MRSA in this study (4.8\%) was in agreement with a study conducted in Mekelle, Ethiopia (6.25\%) [10]; on the contrary, this finding was lower than the results of the studies conducted in Dessie, Ethiopia (12.7\%) [15], 
Table 4 Multivariate analysis of factors associated with S. aureus and MRSA nasal carriage among janitors working at the UoG, 2019

\begin{tabular}{|c|c|c|c|c|c|c|}
\hline Variables & $\begin{array}{l}\text { Nasal carriage of } S \text {. } \\
\text { aureus }(n=101)(n, \%)\end{array}$ & AOR $(95 \% \mathrm{Cl})$ & $P$ value & $\begin{array}{l}\text { Nasal carriage rate } \\
\text { of MRSA }(n=21)(n, \%)\end{array}$ & AOR $(95 \% \mathrm{Cl})$ & $P$ value \\
\hline \multicolumn{7}{|l|}{ Age group (years) } \\
\hline $18-25$ & $32(31.7)$ & & 0.984 & $8(38.1)$ & - & \\
\hline$>25$ & $69(68.3)$ & $1.006(0.580-1.745)$ & & $13(61.9)$ & & \\
\hline \multicolumn{7}{|l|}{ Sex } \\
\hline Male & $4(4)$ & & - & 0 & - & \\
\hline Female & $97(96)$ & & & $21(100)$ & & \\
\hline \multicolumn{7}{|l|}{ Marital status } \\
\hline Single & $30(29.7)$ & - & & $4(19)$ & - & \\
\hline Married & $66(65.3)$ & & & $15(71.4)$ & & \\
\hline Divorced & $5(4.9)$ & & & $2(9.5)$ & & \\
\hline \multicolumn{7}{|l|}{ Educational status } \\
\hline Secondary school or less & $42(41.6)$ & - & - & $11(52.4)$ & $1.178(0.481-3.221)$ & 0.750 \\
\hline Collage or above & $59(58.4)$ & & & $10(47.6)$ & & \\
\hline \multicolumn{7}{|l|}{ Currently living with children } \\
\hline Yes & $27(26.7)$ & - & - & $5(23.8)$ & & - \\
\hline No & $74(73.3)$ & & & $16(76.2)$ & & \\
\hline \multicolumn{7}{|c|}{ Prescribed antibiotics in the last 3 months } \\
\hline Yes & $47(46.5)$ & - & - & $11(52.4)$ & & \\
\hline No & $54(53.5)$ & & & $10(47.6)$ & & \\
\hline \multicolumn{7}{|c|}{ Respiratory tract infection in the last 3 months } \\
\hline Yes & $13(12.9)$ & $2.371(1.029-5.463)$ & 0.043 & $3(14.3)$ & & \\
\hline No & $88(87.1)$ & & & $18(85.7)$ & & \\
\hline \multicolumn{7}{|l|}{ Allergies } \\
\hline Yes & $37(36.6)$ & $0.871(0.508-1.494)$ & 0.616 & $6(28.6)$ & $0.796(0.286-2.217)$ & 0.662 \\
\hline No & $64(63.4)$ & & & $15(71.4)$ & & \\
\hline \multicolumn{7}{|c|}{ Skin infection in the last 3 months } \\
\hline Yes & $46(45.5)$ & $6.378(3.617-11.248)$ & 0.000 & $5(23.8)$ & & \\
\hline No & $55(54.5)$ & & & $16(76.2)$ & & \\
\hline \multicolumn{7}{|c|}{ Wound infection in the last 3 months } \\
\hline Yes & $32(31.7)$ & $2.570(1.383-4.774)$ & 0.003 & $2(9.5)$ & & \\
\hline No & $69(68.3)$ & & & $19(90.5)$ & & \\
\hline \multicolumn{7}{|l|}{ Exposed to body fluids } \\
\hline Yes & $55(54.5)$ & $1.352(0.395-2.298)$ & 0.266 & $10(47.6)$ & & \\
\hline No & $46(45.5)$ & & & $11(52.4)$ & & \\
\hline \multicolumn{7}{|c|}{ Hospital stays in the last 3 months } \\
\hline Yes & $21(20.8)$ & $1.292(0.643-2.595$ & & $9(42.9)$ & $3.151(1.139-8.714)$ & 0.027 \\
\hline No & $80(79.2)$ & & & $12(57.1)$ & & \\
\hline \multicolumn{7}{|c|}{ Living with a hospitalized person } \\
\hline Yes & $36(35.6)$ & $3.151(1.670-5.945)$ & & $8(38.1)$ & $1.551(0.531-4.528)$ & 0.442 \\
\hline No & $65(64.4)$ & & & $13(61.9)$ & & \\
\hline \multicolumn{7}{|l|}{ Job duration as a janitors } \\
\hline$<2$ years & $56(55.4)$ & - & & $11(52.4)$ & $0.597(0.215-1.655)$ & 0.321 \\
\hline$\geq 2$ years & $45(44.6)$ & & & $10(47.6)$ & & \\
\hline \multicolumn{7}{|l|}{ Workplace } \\
\hline Hospital & $65(64.4)$ & $2.127(1.170-3.866)$ & 0.013 & $18(85.7)$ & $3.294(0.822-13.195)$ & 0.092 \\
\hline Non-hospital & $36(35.6)$ & & & $3(14.3)$ & & \\
\hline
\end{tabular}

MRSA Methicillin-resistant S.aureus 
Jimma, Ethiopia (8.4\%) [12] and Gaza strips, Palestine (22.6\%) [16]. But, higher than the results of the studies conducted in Taiwan (2.7\%) [14] and Madagascar (1.3\%) [17]. The difference might be due to variation in study population, sample size, laboratory methods, prevention, and infectious control policies across/within countries and the degree of exposures to the risky environment.

The prevalence of S.aureus was higher in hospitals (29.4\%) than non-hospital janitors (16.7\%); this was statistically significant $(p=0.013)$. This result was in line with those of the studies conducted in Mekelle (hospital janitors $=25.2 \%$ vs. non-hospital janitors $=15.3 \%$ ) [10] and Taiwan (hospital janitors $=15.3 \%$ vs. non-hospital janitors $=13.3 \%$ ) [14]. Moreover, the nasal carriage rate of MRSA among janitors working in hospitals (8.1\%) was higher than among those working in non-hospital janitors $(1.4 \%)$ (But it was not statistically significant). This was in agreement with a study conducted in the USA [healthy care workers (7\%) vs. non-healthcare workers (2\%)] [18]. The higher carriage rate in hospital janitors might be due to high rates of skin infections, wound infections, respiratory infections, frequent use of broadspectrum antibiotics, high chance of exposure to contaminants \& higher selective pressure in the hospital area. However, Most of the janitors working in the hospitals did not follow the correct procedures of medical waste disposal and hand hygiene due to lack of personal protective equipment in the present study. Those asymptomatic colonized individuals have been risky to the hospital or the community because the janitors keep on working unaware of the colonized (unless clinical infection develops), he/she is contributing to the spread of MRSA.

All MRSA isolates were $100 \%$ resistant to penicillin, while the MSSA isolates were $97.5 \%$ resistant to penicillin. Isolates of MRSA and MSSA from hospital janitors were more resistant to the different classes of antimicrobials than isolates from non-hospital janitors. However, the resistance pattern of MRSA isolates to tetracycline, gentamicin, ciprofloxacin, and clindamycin were significantly higher in-hospital than non-hospital janitors. About $30.7 \%$ of the isolates were MDR and a high number of MRSA isolates were multidrug-resistant as compared with the MSSA isolates. This might be due to that, the hospital janitors had higher chances of exposure to infectious patients and contaminated or disposable waste materials.

In the present study, skin infection, wound infection, respiratory infection in the last 3 months, living with a hospitalized person, and working area was found to be more significantly associated with S.aureus than MRSA. Besides, hospitalization within the last 3 months has been found significantly associated with MRSA. This confirms that nasal carriage of S.aureus has been associated with an increased risk for skin infection, wound infection, and respiratory infection. The high colonization rate among hospital janitors might be since hospital janitors had a higher chance of exposure to contaminated and disposable waste materials.

\section{Limitation of the study}

The study has some limitations, We were unable to perform vancomycin minimum inhibitory concentration and use advanced molecular techniques due to budget constraint.

\section{Conclusion}

The present study revealed that high MSSA and MRSA isolates were isolated in hospitals as compared to nonhospital janitors and a large number of resistances to the tested antibiotics were found in the hospital isolates. Moreover, hospitalizations were significantly associated with MRSA. Accordingly, we advocate regular screening of carriers on apparently healthy cleaners is required for the prevention of nosocomial infections.

\section{Abbreviations \\ MDR: Multiple Drug Resistance; MRSA: Methicillin resistance Staphylococcus aureus; MSSA: Methicillin-susceptible Staphylococcus aureus; UoG: University of Gondar.}

\section{Acknowledgements}

We would like to thank the study participants for their willingness to participate in the study.

\section{Authors' contributions}

SA conceived the study designed, data collection, performed the sample collection and laboratory investigations, conducted data analysis, and interpretation. MT and WA conceived the study, designed data collection, interpreted the results, and reviewed the initial and final drafts of the manuscript. All authors read and approved the final manuscript.

\section{Funding}

No specific grant.

\section{Availability of data and materials}

All data generated or analyzed during this study were included in this article.

\section{Ethics approval and consent to participate}

This research was conducted after obtaining ethical clearance from Research and Ethical Review Committee of School of Biomedical and Laboratory Sciences, College of Medicine and Health Sciences, University of Gondar, and support letters were obtained from human resource directorate of the UoG before data collection. Written informed consent was obtained from each study participant.

\section{Consent for publication \\ Not applicable.}

\section{Competing interests}

The authors declare that they have no competing interests. 
Received: 18 June 2020 Accepted: 10 October 2020

Published online: 19 October 2020

\section{References}

1. Grundmann H, Aires-de-Sousa M, Boyce J, Tiemersma E. Emergence and resurgence of methicillin-resistant Staphylococcus aureus as a publichealth threat. Lancet. 2006;368:874-85.

2. Stefani S, Goglio A. Methicillin-resistant Staphylococcus aureus: related infections and antibiotic resistance. Int J Infect Dis. 2010;14:S19-22.

3. Tilahun B, Faust AC, McCorstin P, Ortegon A. Nasal colonization and lower respiratory tract infections with methicillin-resistant Staphylococcus aureus. Am J Crit Care. 2015;24(1):8-12.

4. Salgado CD, Farr BM, Calfee DP. Community-acquired methicillin-resistant Staphylococcus aureus: a meta-analysis of prevalence and risk factors. Clin Infect Dis. 2003;36(2):131-9.

5. Mork RL, Hogan PG, Muenks CE, Boyle MG, Thompson RM, Sullivan ML, Morelli JJ, Seigel J, Orscheln RC, Wardenburg JB, Gehlert SJ. Longitudinal, strain-specific Staphylococcus aureus introduction and transmission events in households of children with community-associated methicillinresistant Staphylococcusaureus skin and soft tissue infection: a prospective cohort study. Lancet Infect Dis. 2020;20(2):188-98.

6. Reta A, Wubie M, Mekuria G. Nasal colonization and antimicrobial susceptibility pattern of Staphylococcus aureus among pre-school children in Ethiopia. BMC Res Notes. 2017:10(1):746.

7. Balta B, Derbie F. Nasal carriage of methicillin resistant Staphylococcus aureus strains among inpatients of Jimma hospital, South Western Ethiopia. Ethiop J Health Sci. 2003;13(2):107-15.

8. Reta A, Mengist A, Tesfahun A. Nasal colonization of methicillin-resistant Staphylococcus aureus in Ethiopia: a systematic review and meta-analysis. Ann Clin Microbiol Antimicrob. 2019;18(1):1-2.

9. Charles LE, Loomis D, Demissie Z. Occupational hazards experienced by cleaning workers and janitors: a review of the epidemiologic literature. Work. 2009:34(1):105-16.

10. Kahsay AG, Hagos DG, Abay GK, Mezgebo TA. Prevalence and antimicrobial susceptibility patterns of methicillin-resistant Staphylococcus aureus among janitors of Mekelle University, North Ethiopia. BMC Res Notes. 2018;11(1):294

11. CLSI. Performance standards for antimicrobial susceptibility testing CLSI supplement M10029. Wayne: Clinical and Laboratory Standards Institute; 2019.

12. Efa F, Alemu Y, Beyene G, Gudina EK, Kebede W. Methicillin-resistant Staphylococcus aureus carriage among medical students of Jimma University, Southwest Ethiopia. Heliyon. 2019;5(1):e01191.

13. Charlebois ED, Bangsberg DR, Moss NJ, Moore MR, Moss AR, Chambers $H F$, Perdreau-Remington F. Population-based community prevalence of methicillin-resistant Staphylococcus aureus in the urban poor of San Francisco. Clin Infect Dis. 2002;34:425-33.

14. Chang CJ, Chen NC, Lao CK, Huang YC. Nasal Staphylococcus aureus and methicillin-resistant $S$. aureus carriage among janitors working in hospitals in Northern Taiwan. PLoS ONE. 2015;10(9):e0138971.

15. Shibabaw A, Abebe T, Mihret A. Antimicrobial susceptibility pattern of nasal Staphylococcus aureus among Dessie Referral Hospital health care workers, Dessie Northeast Ethiopia. Int J Infect Dis. 2014:25:22-5.

16. Al Laham N. Detection and antibiotic resistance pattern of Staphylococcus aureus and MRSA isolated from healthcare workers nares at Gaza Hospitals. Palestine Int Arab J Antimicrob Agents. 2016. https://doi. org/10.3823/779.

17. Hogan B, Rakotozandrindrainy R, Al-Emran H, Dekker D, Hahn A, Jaeger A, Poppert S, Frickmann H, Hagen RM, Micheel V, Crusius S. Prevalence of nasal colonisation by methicillin-sensitive and methicillin-resistant Staphylococcus aureus among healthcare workers and students in Madagascar. BMC Infect Dis. 2016;16(1):420.

18. Kuehnert MJ, Kruszon-Moran D, Hill HA, McQuillan G, McAllister SK, Fosheim G, McDougal LK, Chaitram J, Jensen B, Fridkin SK, Killgore G. Prevalence of Staphylococcus aureus nasal colonization in the United States, 2001-2002. J Infect Dis. 2006;193(2):172-9.

\section{Publisher's Note}

Springer Nature remains neutral with regard to jurisdictional claims in published maps and institutional affiliations.
Ready to submit your research? Choose BMC and benefit from:

- fast, convenient online submission

- thorough peer review by experienced researchers in your field

- rapid publication on acceptance

- support for research data, including large and complex data types

- gold Open Access which fosters wider collaboration and increased citations

- maximum visibility for your research: over 100M website views per year

At BMC, research is always in progress.

Learn more biomedcentral.com/submissions 